\title{
ANALISA TEGANGAN POROS RODA GERBONG KERETA API DENGAN METODE ELEMEN HINGGA
}

\author{
Nana Supriyana \\ Program Studi Teknik Mesin \\ STT Wiworotomo Purwokerto \\ Email: Nana.sttw@gmail.com \\ Akhmad Kholidin \\ Program Studi Teknik Mesin \\ STT Wiworotomo Purwokerto \\ Email: kholidinptkai@gmail.com
}

\begin{abstract}
ABSTRAK
Poros roda kereta merupakan salah satu bagian yang berhubungan langsung dengan keselamatan penumpang maupun bagian lain dalam perjalanan kereta api. Penelitian untuk mengetahui distribusi tegangan yang dialami oleh poros sehingga diketahui letak area kritis pembebanan poros roda kereta, apakah area kritis roda kereta akibat pembebanan terletak pada asnaff atau astap poros roda kereta dan kasus beban impact karena roda benjol atau rata bidang jalan. Simulasi pembebanan menggunakan software ANSYS 12.0 dengan tiga kondisi pembebanan poros roda kereta. Pertama saat menerima beban statis kereta sebesar 4,625 ton per leher poros kereta, kedua saat kereta berjalan sehingga terjadi beban dinamis sebesar 8,9 ton dan ketiga saat terjadinya beban impact dari adanya roda benjol, kerataan bidang jalan atau ketidak rataan jalan rel sebesar sepuluh kali beban statis atau 46,25 ton. Dari hasil simulasi didapat tegangan maksimum terjadi pada node nomor 32 dan nomor 180 yang terletak pada peralihan diameter asnaff ke diameter astap, area ini pada jarak 285,2 $\mathrm{mm}$ dari ujung poros. Nilai tegangan maksimum yang diterima poros pada pengkondisian beban tertinggi akibat beban impact yang dimungkinkan karena roda benjol sebesar $112,3 \mathrm{~N} / \mathrm{mm}^{2}$ dan $109,4 \mathrm{~N} / \mathrm{mm}^{2}$ masih dalam batas aman karena tidak lebih besar dari tegangan yang diijinkan pada teori kegagalan von misses yaitu $225 \mathrm{~N} / \mathrm{mm}^{2}$.
\end{abstract}

Kata kunci: poros, ansys, tegangan.

\begin{abstract}
Axle shaft is one part that relates directly to the safety of passengers and other parts of the train journey. Research to determine the distribution of stress experienced by the shaft in order to know the location of critical areas of the axle load trains, is a critical area due to the imposition of the wheels located on asnaff or astap wagon wheel axle and wheel load cases impact due to road bumps or flat field. Loading simulation using ANSYS 12.0 software with three train axle loading conditions. The first train when receiving a static load of 4.625 tons per axle neck trains, both when the train runs resulting in a dynamic load of 8.9 tons and the third time of the impact load on the wheel bumps, flatness field of road or rail road unevenness as much as ten times the load static or 46.25 tons. From the simulation results obtained maximum stress occurs on node number 32 and number 180 are located in the transition asnaff diameter to diameter astap, this area at a distance of $285.2 \mathrm{~mm}$ from the end of the shaft. The maximum stress value received in the conditioning shaft highest burden due to the impact load is possible because the wheels bumps of $112.3 \mathrm{~N} / \mathrm{mm} 2$ and 109, $4 \mathrm{~N} / \mathrm{mm} 2$ still within safe limits because it is not greater than the allowable voltage on the theory that the failure of von misses $225 \mathrm{~N} / \mathrm{mm} 2$.
\end{abstract}

Keywords: shaft, ansys, stress.

\section{PENDAHULUAN}

Poros roda merupakan salah satu komponen dari beberapa komponen yang terdapat pada sarana perkeretaapian. Poros dirangkai dengan dua keping roda menjadi satu kesatuan perangkat roda atau wheel set dan berputar dengan keping roda karena terpasang kedalam naff / hub.

M. Subyanto pada tahun 1982 [1] menjelaskan pada perhitungan kekuatan gandar (poros roda kereta) dan menentukan besarnya tegangan pada batas lelah untuk bahan gandar dengan fatique test. Pramono dan Slamet pada tahun 2007 dari Dipo Kereta Purwokerto [2] dalam aspek pengukuran pada 
perawatan berkala di DipoPemeriksaan dilakukan menyeluruh terhadap kelengkapan bogie termasuk didalamnya pemeriksaan pelumasan dan bearing, pemeriksaan keausan flens dan bidang jalan roda serta pemeriksaan keretakan poros roda kereta metode undistruction test menggunakan alat ultrasonic test. Setelah proses scan selesai kemudian dilakukan evaluasi hasil periksa apakah terdapat indikasi keretakan pada poros atau tidak. Apakah pulse/echo yang timbul sepanjang poros menunjukan indikasi retak atau karena memantul pada perbedaan diameter sepanjang poros khususnya diantara astap dan asnaff. Hasil periksa ini yang menjadi salah satu dasar kereta dapat Siap Operasi (SO) atau Tidak Siap Operasi (TSO).

Taufik Akbar Iskandar Chandra pada tahun 2009 [3] mensimulasikan pembebanan gaya berat pada mill shaft roll shell (poros pada mesin giling tebu) di pabrik gula sei semayang dengan metode elemen hingga dan mendapatkan hasil simulasi kemudian dibandingkan dengan perhitungan teori kegagalan von misses, kondisi tidak aman akibat gaya yang timbul akibat torsi dapat diketahui, terjadi pada torsi pertama karena distribusi tegangan maksimum terjadi lebih besar 282x106 N/m2 dari kekuatan tarik bahan $225 \times 106 \mathrm{~N} / \mathrm{m} 2$. Hasil studi terhadap kondisi poros kereta api diantaranya menurut Siswosuwarno, dan mardjono dalam penelitianya pada tahun 2010 [4] menjelaskan bahwa roda benjol menyebabkan terjadinya beban impact, baik kepada rel, maupun kepada roda. Makin dalam bagian yang benjol, makin besar beban impactnya. Benjolan sebesar $4 \mathrm{~mm}$ pada kecepatan $70 \mathrm{~km} / \mathrm{jam}$ mengakibatkan beban impact 10 kali lebih besar dari beban statiknya (studi/penelitian di Belanda). Rekomendasi yang diberikan pada roda benjol adalah perlu segera dibubut ulang. Biyanto Nur dan N Supriyana tahun 2012 dalam penelitian analisa kegagalan poros roda menggunakan pengujian bahan, simulasi ansys dan perhitungan $\mathrm{MEH}$, STTW Purwokerto [5] mendapatkan kesimpulan bahwa poros yang mengalami kegagalan masih memenuhi standar penggunaan dan kegagalan dimungkinkan karena pembebanan yang diterima poros terlalu besar.

Maksud penelitian ini adalah untuk mengetahui distribusi tegangan yang dialami oleh poros sehingga diketahui letak area kritis pembebanan poros roda kereta. Apakah area kritis roda kereta akibat pembebanan terletak pada asnaff atau astap, selain tersebut didapatkan nilai tegangan maksimum yang terjadi pada simulasi kasus beban impact karena roda benjol atau rata bidang jalan, kondisi dalam penelitian ini yaitu poros roda kereta tipe CC diameter astap $119 \mathrm{~mm}$, dampak adanya faktor cacat material dan thermal diabaikan.

\section{METODOLOGI PENELITIAN}

\subsection{Desain Penelitian}

Desain penelitian ini adalah mensimulasikan distribusi tegangan akibat pembebanan berat kereta pada poros roda kereta dengan tiga kondisi yaitu poros dengan pembebanan berat statis kereta, poros dengan pembebanan berat dinamis kereta dan poros dengan pembebanan impact akibat roda benjol, kerataan bidang jalan atau ketidakrataan jalan rel serta membandingkan hasil simulasi software ANSYS 12.0 dengan hasil teori kegagalan (Von Misses).

\subsection{Alat Penelitian}

Pembuatan simulasi menggunakan hardware berupa Personal Computer (PC) dan software yang digunakan adalah ANSYS versi 12.0.

\subsection{Bahan Penelitian}

1) Poros Roda Kereta

Perangkat roda tipe $\mathrm{CC}$ dengan spesifikasi teknisnya adalah sebagai berikut:

a. Panjang poros $=1815 \mathrm{~mm}$

b. Jarak bantalan radial /jarak titik tumpu(j) $=1590 \mathrm{~mm}$

c. Jarak telapak roda $(\mathrm{g})=1120 \mathrm{~mm}$

d. Diameter astap $=119 \mathrm{~mm}$

e. Diameter keping roda $=774 \mathrm{~mm}, \mathrm{r}=387 \mathrm{~mm}$

f. Beban poros maksimal $=14 \mathrm{ton}=14.000 \mathrm{~kg}$

g. Poros roda kereta terbuat dari baja tempa roll setara dengan JIS E 4502 SFA 60B dengan Modulus Elasity= $210 \mathrm{GPa}$ (General Properties of Steels 2009 eFunda)

2) Kereta dengan spesifikasi teknik sebagai berikut:
a. Berat Total $=40$ ton $=40.000 \mathrm{~kg}$
b. Tipe Bogie $=$ TB -398
c. Berat perangkat roda $=750 \mathrm{~kg}$ 


\subsection{Tempat Penelitian}

Penelitian dilaksanakan di Dipo Kereta Purwokerto dan lab. komputer STT Wiworotomo.

\subsection{Prosedur Penelitian}

Langkah prosedur penelitian yaitu dengan memperhitungkan tiga kondisi pembebanan yang terjadi pada poros roda yaitu:

1) Pada saat poros roda hanya mengalami beban statis dari seluruh bagian kereta yang ditumpu yaitu dari berat body atau badan kereta, bogie, tangki air, unit AC, perlengkapan rangka bawah dan berat kursi dan penumpang seperti digambarkan pada gambar 1 .

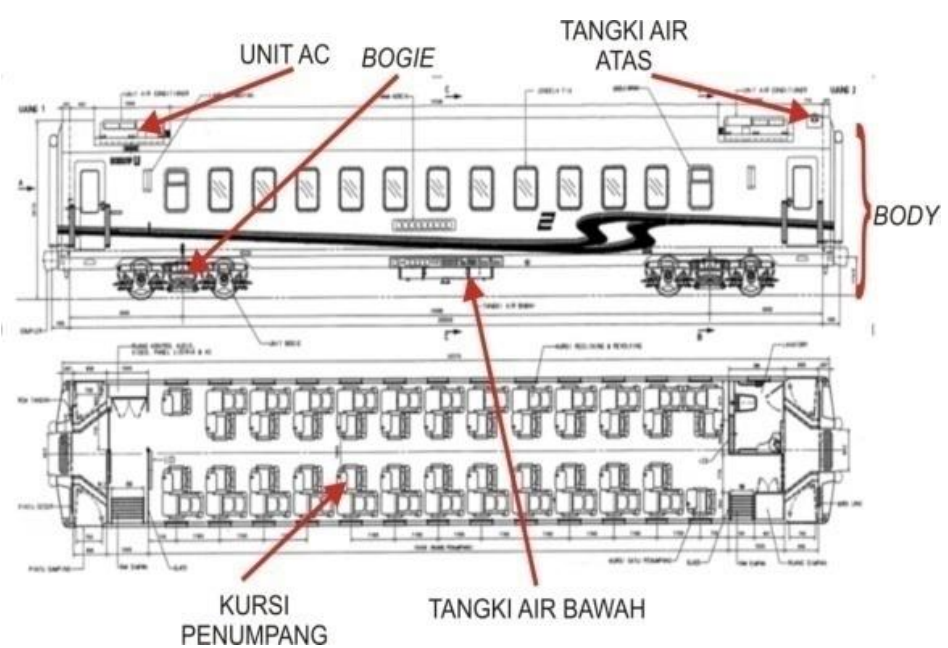

Gambar 1. Bagian Kereta

2) Pada saat poros mengalami beban yang terjadi saat kereta berjalan yaitu beban dinamis 0,4 kali beban statis dan beban dari adanya gaya getaran horisontal.

3) Pada saat poros mengalami beban impact sebesar 10 kali beban statis kereta yang dapat ditimbulkan dari roda benjol maupun kerataan bidang jalan tapak roda atau ketidakrataan jalan rel.

Kemudian melakukan pembuatan simulasi ANSYS yang digunakan adalah dengan pandangan 2 dimensi, seperti diperlihatkan pada gambar 2.

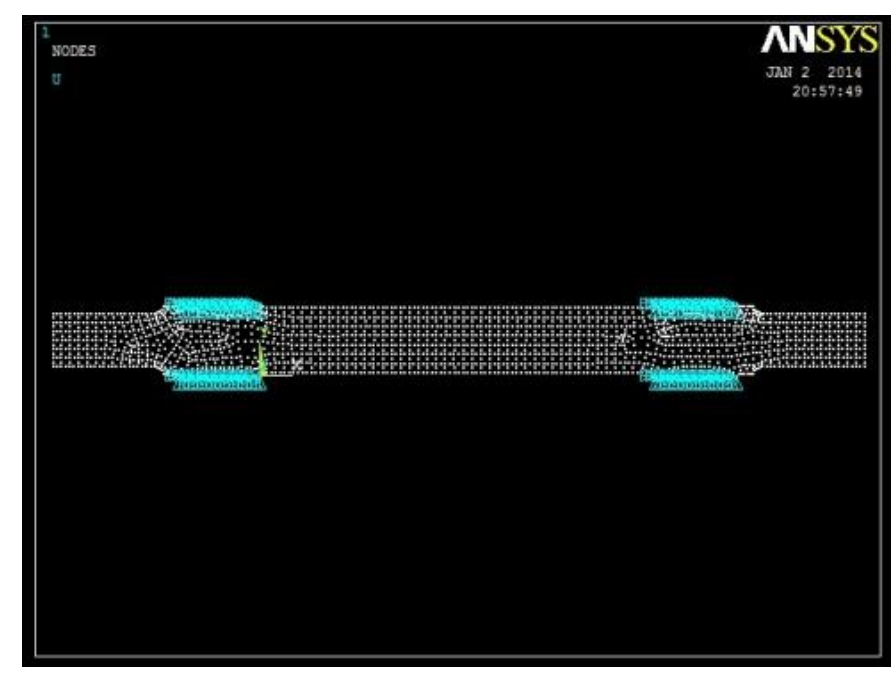

Gambar 2. Tampilan Hasil Displacement Pada Kedua Asnaff Poros 
Langkah selanjutnya dilakukan penerapan beban (load) dengan pemberian gaya:

1) Kondisi pembebanan pertama yaitu beban yang ditumpu oleh poros roda kereta dari beban statis kereta $\left(\mathrm{W}_{\mathrm{A}}\right)$, Dimana berat total kereta $=40.000 \mathrm{~kg}$, Jumlah Perangkat Roda $=4$ set, Berat 4 perangkat roda@750 kg=3.000 kg.

$\mathrm{W}_{\mathrm{A}} \quad=\frac{40.000-3.000}{4}=9.250 \mathrm{~kg}$

Maka beban statis yang ditumpu pada satu leher poros adalah separuh beban satu gandar $=4.625$ $\mathrm{kg}$

$$
\begin{aligned}
& =4,625 \mathrm{~T} \\
& =45.355,76 \mathrm{~N}(1 \mathrm{~T}=9806,65 \mathrm{~N})
\end{aligned}
$$

2) Kondisi pembebanan kedua yaitu kondisi pembebanan dari beban dinamis kereta yang ditumpu oleh poros, beban dinamis pada satu leher $\left(\mathrm{W}_{0}\right)$.

$\mathrm{W}_{0} \quad=\frac{1.4 \mathrm{~W}_{\mathrm{A}}}{2} \quad=6.475 \mathrm{~kg}$

Dan beban dari adanya gaya getaran horizontal $(\mathrm{P})$ :

$$
\begin{aligned}
\mathrm{P} & =0,3 \times \mathrm{W}_{\mathrm{A}} \\
& =2.775 \mathrm{~kg} \\
\mathrm{Q}_{\mathrm{Q}} & =\mathrm{P} \times \frac{\mathrm{h}}{\overline{\mathrm{j}}} \\
& =2.386 \mathrm{~kg}
\end{aligned}
$$

Nilai h adalah tinggi titik berat kereta dimana berat per bagian:

G1 = 9 ton (bogie 2 set), G2 = 1,4 ton (perlengkapan rangka bawah), G3 = 4,6 ton (kursi + penumpang), G4 $=24$ ton (body kereta), G5 =0,2 ton (tangki air atas), G6 =0,8 ton (AC 2 unit) dan tinggi per bagian:

$\mathrm{Y} 1=0,4 \mathrm{~m} . \mathrm{Y} 2=0,6 \mathrm{~m} . \mathrm{Y} 5=3 \mathrm{~m} . \mathrm{Y} 4=1,7 \mathrm{~m} . \mathrm{Y} 3=1,4 \mathrm{~m} . \mathrm{Y} 6=3 \mathrm{~m}$.

sehingga persamaannya menjadi:

$\overline{\mathrm{Y}}=(\mathrm{G} 1 . \mathrm{Y} 1+\mathrm{G} 2 . \mathrm{Y} 2+\mathrm{G} 3 . \mathrm{Y} 3+\mathrm{G} 4 . \mathrm{Y} 4+\mathrm{G} 5 . \mathrm{Y} 5+\mathrm{G} 6 . \mathrm{Y} 6) /(\mathrm{G} 1+\mathrm{G} 2+\mathrm{G} 3+\mathrm{G} 4+\mathrm{G} 5)$

$\overline{\mathrm{Y}}=(9.0,4+1,4.0,6+4,6.1,4+24.1,7+0,2.3+0,8.3) /(9+1,4+4,6+24+0,2+0,8)$

$\overline{\mathrm{Y}}=1,367 \mathrm{~m}=136,7 \mathrm{~cm}($ nilai $\mathrm{h})$

Beban dinamis keseluruhan yaitu diambil dari beban dinamis pada satu leher $\left(\mathrm{W}_{0}\right)$ ditambah beban dari adanya gaya getaran horizontal $(\mathrm{P})$ sebesar:

$=6.475 \mathrm{~kg}+2.386 \mathrm{~kg}=8.861 \mathrm{~kg}=8,9=87279,2 \mathrm{~N}$

3) Kondisi pembebanan ketiga yaitu dengan beban yang ditumpu oleh poros adalah beban impact sebesar 10 kali beban statis. Maka beban impact yang dimasukan pada kondisi ketiga sebesar:

$=10 \times 4,625=46,25=453.557,6 \mathrm{~N}$

Hasil simulasi beberapa kondisi pembebanan:

1) Kondisi Pembebanan 1

Pada kondisi pembebanan dengan beban stastis kereta dengan titik pembebanan pada kedua titik tumpu roda seperti terlihat pada gambar 3.

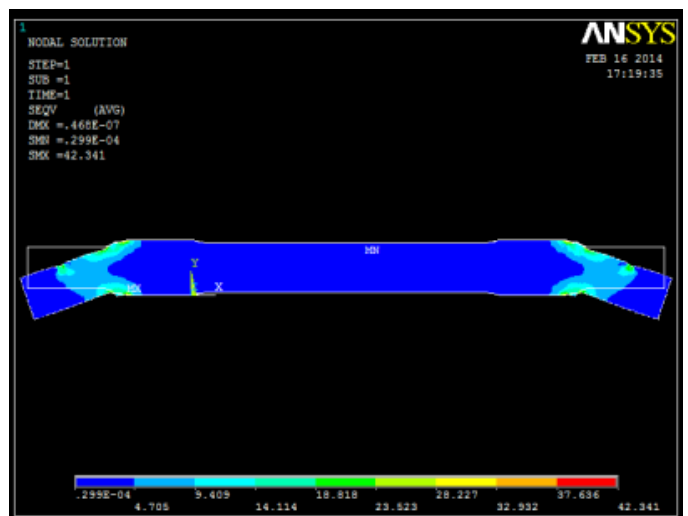

Gambar 3. Hasil Simulasi Kondisi Pembebanan 1

Dari hasil simulasi diperoleh tegangan maksimum terletak pada node 32 dengan nilai sebesar $11,230 \mathrm{~N} / \mathrm{mm}^{2}$ dan node 180 sebesar $10,940 \mathrm{~N} / \mathrm{mm}^{2}$ pada kedua leher poros, seperti diperlihatkan pada Gambar 4. 

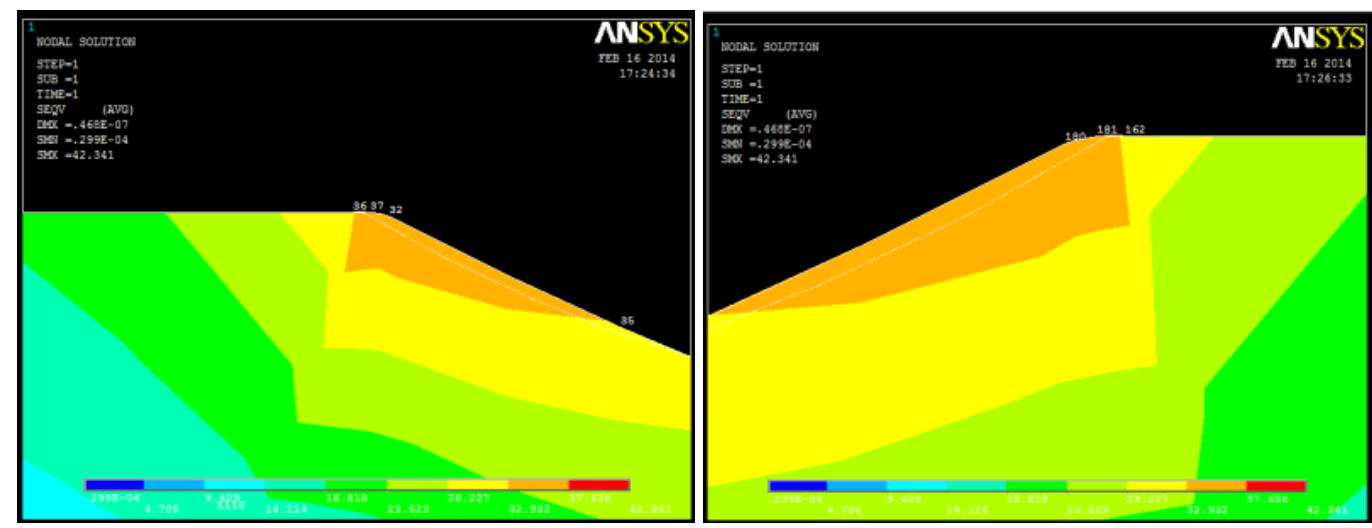

Gambar 4. Gradiasi Warna Tegangan Maks. Node No. 32 dan 180 Pada Kondisi 1

2) Kondisi Pembebanan 2

Pada kondisi pembebanan dengan beban dinamis kereta dengan titik pembebanan pada titik tumpu roda diperoleh tegangan maksimum pada kedua leher poros terletak pada node 32 dengan nilai sebesar $21,610 \mathrm{~N} / \mathrm{mm}^{2}$ dan node 180 sebesar $21,051 \mathrm{~N} / \mathrm{mm}^{2}$ pada kedua leher poros seperti terlihat pada gambar 5 .

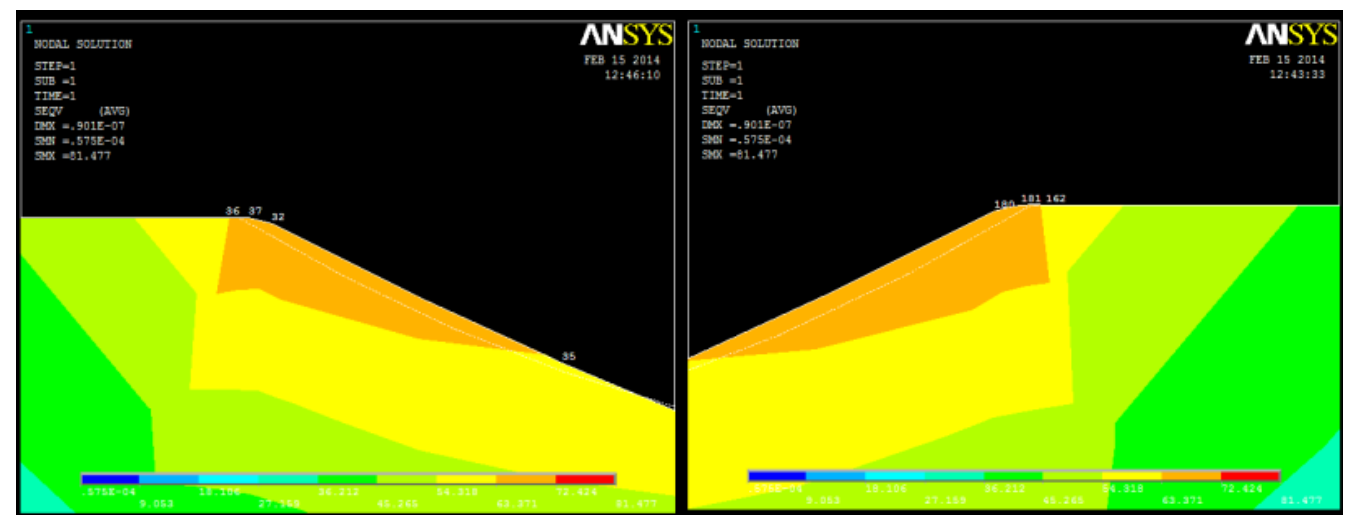

Gambar 5. Gradiasi Warna Tegangan Maks. Node No. 32 dan 180 Pada Kondisi 2

3) Kondisi Pembebanan 3

Pada kondisi pembebanan dengan beban impact akibat roda benjol dengan titik pembebanan pada titik tumpu roda diperoleh tegangan maksimum pada kedua leher poros terletak pada node 32 dengan nilai sebesar 112,3 N/mm² dan node 180 sebesar $109,4 \mathrm{~N} / \mathrm{mm}^{2}$ pada kedua leher poros seperti diperlihatkan pada gambar 6.

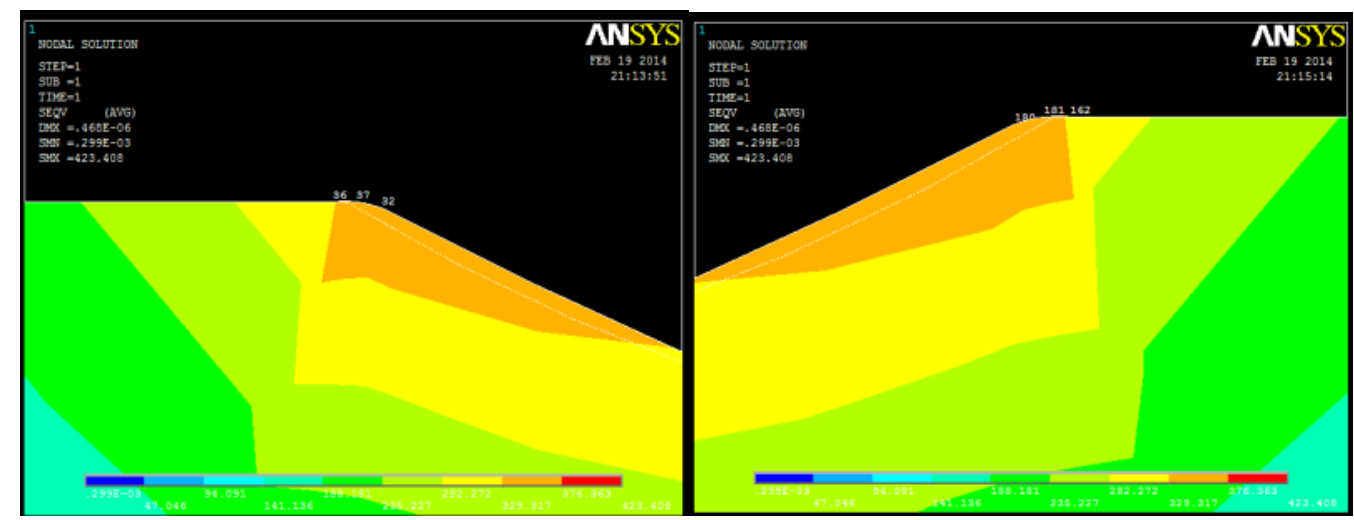

Gambar 6. Gradiasi Warna Tegangan Maksimum Node No. 32 Pada Kondisi 3 


\section{ANALISA DAN PEMBAHASAN}

Dengan melihat hasil simulasi pada tiga kondisi dapat diperoleh letak tegangan maksimum poros berada pada node no. 32 dan no. 180, seperti pada Tabel 1.

Tabel 1. Tegangan maksimum hasil simulasi pada poros roda

\begin{tabular}{lcccc}
\hline \multirow{2}{*}{ Kondisi Beban } & \multicolumn{2}{c}{ Leher $\boldsymbol{A}$} & \multicolumn{2}{c}{ Leher B } \\
\cline { 2 - 4 } & Teg. maks $^{*}\left(\mathbf{N} / \mathbf{m m}^{\mathbf{2}}\right)$ & No. node & Teg. $\mathbf{m a k s}\left(\mathbf{N} / \mathbf{m m}^{\mathbf{2}}\right)$ & No. node \\
\hline Kondisi 1 & 11,230 & 32 & 10,940 & 180 \\
Kondisi 2 & 21,610 & 32 & 21,051 & 180 \\
Kondisi 3 & 112,30 & 32 & 109,40 & 180 \\
\hline
\end{tabular}

Kedua node tersebut terletak pada area terluar asnaff yang berada pada 285,2 $\mathrm{mm}$ dari ujung poros dan melihat teori kegagalan von misses, agar material tidak terjadi kegagalan maka tegangan maksimum yang terjadi tidak boleh melebihi tegangan von misses $\left(\mathrm{N} / \mathrm{mm}^{2}\right)$. Yield strength bahan poros roda diambil dari nilai $450 \mathrm{Mpa}$. Yield strength atau Sy dari bahan poros:

$\frac{5 y}{2}=\frac{450}{2}=225 \mathrm{~N} / \mathrm{mm}^{2}$

Pada pengujian dengan tegangan maksimum paling tinggi yaitu pada kondisi 3, nilai tegangan yang terjadi sebesar $112,3 \mathrm{~N} / \mathrm{mm}^{2}$ dan $109,4 \mathrm{~N} / \mathrm{mm}^{2}$ sehingga pada pengkondisian beban poros roda kereta masih dalam batas aman karena tidak lebih besar dari tegangan yang diijinkan pada teori kegagalan von misses yaitu $225 \mathrm{~N} / \mathrm{mm}^{2}$.

\section{KESIMPULAN}

Berdasarkan hasil perhitungan dan simulasi menggunakan software ansys diperoleh beberapa kesimpulan yaitu:

1) Poros roda kereta mengalami distribusi tegangan yang bervariasi, distribusi tegangan relatif tinggi terjadi pada area perubahan diameter poros dari diameter asnaff sampai dengan diameter astap.

2) Tegangan maksimum yang terjadi terletak pada node no. 32 dan no. 180 yaitu berada pada jarak $285,2 \mathrm{~mm}$ dari ujung poros dan nilai tegangan maksimum yang diterima poros pada pengkondisian beban tertinggi akibat beban impact sebesar 112,3 N/mm² dan 109, $4 \mathrm{~N} / \mathrm{mm}^{2}$ masih dalam batas aman karena tegangan yang diijinkan pada teori kegagalan von misses yaitu $225 \mathrm{~N} / \mathrm{mm}^{2}$.

\section{DAFTAR PUSTAKA}

[1] Subyanto, M. 1982. “Dinamika Kendaraan Rel, Suatu Pembahasan Mengenai Gerakan Perjalanan Kereta Api Diatas Jalan-Baja Ditinjau Dari Segi Operasi Teknis” Bandung, CV. Komala.

[2] Pramono, Slamet. 2007. “Aspek Pengukuran Pada Perawatan Berkala di Dipo” Purwokerto, Dipo Kereta Purwokerto.

[3] Akbar Iskandar Chandra, Taufik. 2009. "Simulasi Pembebanan Gaya Berat Pada Mill Shaft Roll Shell Di Pabrik Gula Sei Semayang Dengan Metode Elemen Hingga” Medan, Univ. Sumatera Utara.

[4] Siswosuwarno, Mardjono. 2010. "Beberapa Hasil Penyelidikan PLH: Faktor Penyebab \& Rekomendasi” Tegal, Diklap Sarana BYTG-ITB Bandung.

[5] Biyanto Nur, Supriyana Nana. 2012, “Analisa Kegagalan Poros Roda Menggunakan Pengujian Bahan, Simulasi Ansys Dan Perhitungan MEH” Purwokerto, STTW. 